\title{
Effects of training and competition on the sleep of elite athletes: a systematic review and meta-analysis
}

\author{
Spencer Stuart Haines Roberts, Wei-Peng Teo, Stuart Anthony Warmington
}

- Additional material is published online only. To view please visit the journal online (http://dx.doi.org/10.1136/ bjsports-2018-099322).

Institute for Physical Activity and Nutrition, School of Exercise and Nutrition Sciences, Deakin University, Burwood, Victoria, Australia

Correspondence to Spencer Stuart Haines Roberts, School of Exercise and Nutrition Sciences, Deakin University, Burwood, VC 3125, Australia; rspen@deakin.edu.au

Accepted 6 August 2018 Published Online First 14 September 2018
ABSTRACT

Objectives To characterise the sleep of elite athletes and to identify factors associated with training and competition that negatively affect sleep.

Design Prognosis systematic review.

Data sources Three databases (PubMed, SCOPUS and SPORTDiscus) were searched from inception to 26 February 2018.

Eligibility criteria for selecting studies Included studies objectively reported total sleep time (TST) and/or sleep efficiency (SE) in elite athletes. Studies were required to be observational or to include an observational trial.

Results Fifty-four studies were included. During training, many studies reported athletes were unable to achieve TST ( $n=23 / 41)$ and/or SE $(n=16 / 37)$ recommendations. On the night of competition, most studies reported athletes were unable to achieve TST $(n=14 / 18)$ and/or SE $(n=10 / 16)$ recommendations. TST was shorter (60 min) the night of competition compared with previous nights. SE was lower (1\%) the night of competition compared with the previous night. TST was shorter the night of night competition (start $\geq 18: 00$; $80 \mathrm{~min}$ ) and day competition ( $20 \mathrm{~min}$ ) compared with the previous night. SE was lower $(3 \%-4 \%)$ the night of night competition but unchanged the night of day competition compared with previous nights. Early morning training (start <07:00), increases in training load (>25\%), late night/early morning travel departure times, eastward air travel and altitude ascent impaired sleep.

Conclusion Athletes were often unable to achieve sleep recommendations during training or competition periods. Sleep was impaired the night of competition compared with previous nights. Early morning training, increases in training load, travel departure times, jet lag and altitude can impair athletes' sleep.

PROSPERO registration number CRD42017074367.

\section{INTRODUCTION}

Sleep is associated with many physiological processes that may facilitate recovery from, and adaptation to, athletic training and competition. ${ }^{1}$ During sleep, anabolic metabolism is upregulated, ${ }^{2}$ procedural memories are consolidated ${ }^{3}$ and immune responses are augmented. ${ }^{4}$ Not surprisingly, many athletes identify sleep as the most important recovery behaviour for athletic success. ${ }^{5}$ Extending sleep may be beneficial for sports-specific skill execution. ${ }^{6}$ Nightly sleep duration has been positively correlated with team netball performance ${ }^{7}$ and associated with injury risk in adolescent athletes. ${ }^{8}$

It is important to understand how the demands of training and competition affect sleep, and this has become a priority for coaches and scientists. ${ }^{9}$ It is recommended that adults sleep at least 7 hours per night and achieve a sleep efficiency (ie, time asleep as a percentage of time in bed) of at least $85 \%$ on a regular basis to promote health. ${ }^{10}{ }^{11}$ However, there is a high prevalence of insomnia symptoms among athletes. ${ }^{9}$ Much of the research examining athletes' sleep has been derived from subjective tools (eg, diaries). ${ }^{12}$ This is a problem because subjective tools, while useful for monitoring large cohorts, typically correlate poorly with objective data. ${ }^{13}$

The 'gold standard' for sleep monitoring is polysomnography (PSG), which uses surface electrodes to monitor physiological parameters such as brain, muscle, heart and respiratory activity. ${ }^{14}$ PSG is particularly useful for investigating sleep pathologies, including sleep-disordered breathing ${ }^{15}$ and sleep disturbances caused by concussion. ${ }^{16}$ However, PSG is expensive and requires specialised laboratory equipment, making it impractical for monitoring athletes in the field. ${ }^{17}$ Actigraphy, on the other hand, uses accelerometers embedded in portable devices to record movements that can be analysed using algorithms that estimate sleep quality and quantity. ${ }^{18}$ Actigraphy is inexpensive and can be administered with minimal impact on habitual sleep or training routines. As such, actigraphy is the preferred method for objectively monitoring the sleep of athletes. ${ }^{17}$

In recent years, growing interest in understanding the sleep of athletes has seen an increase in published studies, such that objective data are now readily available. Therefore, in this systematic review we aimed to characterise the sleep of athletes in the context of current sleep recommendations, and to examine whether there were training and competition factors that negatively affected sleep.

\section{METHODS}

This review conformed to the Meta-Analysis of Observational Studies in Epidemiology (MOOSE) guidelines for Meta-Analyses and Systematic Reviews of Observational Studies, ${ }^{19}$ and has adopted the Preferred Reporting Items for Systematic Reviews and Meta-Analyses (PRISMA), ${ }^{20}$ with PROSPERO trial registration number CRD42017074367.

\section{Search strategy}

Three electronic databases (PubMed, SCOPUS and SPORTDiscus) were searched from inception to 26 February 2018 using combinations of the following keywords: sleep, elite, competitive, athlete/s, sport and player/s (online supplementary file 1). Reference lists of relevant studies were also cross-checked. Figure 1 illustrates the search process. 


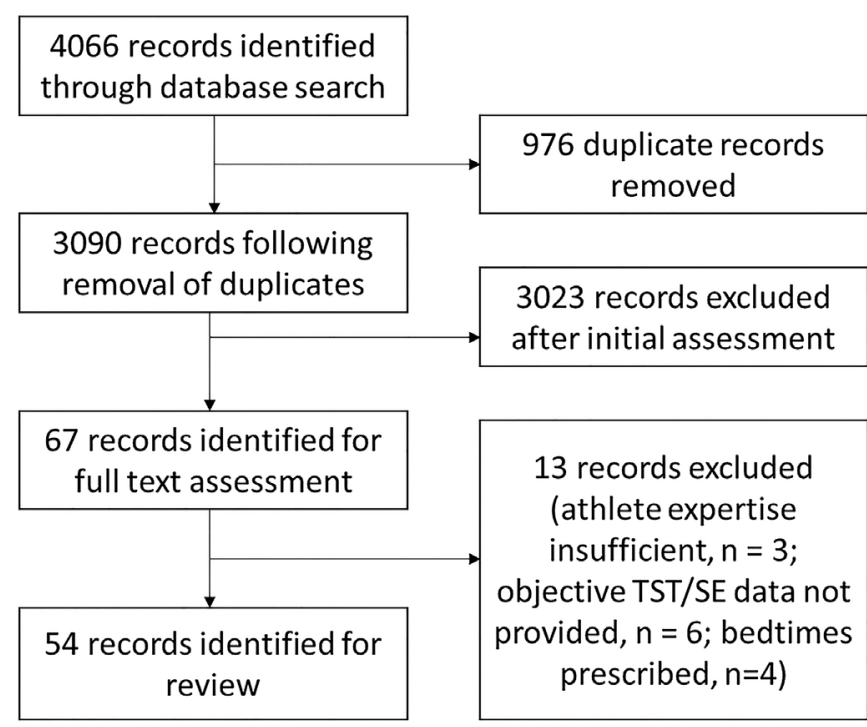

Figure 1 Preferred Reporting Items for Systematic Reviews and Meta-Analyses flow chart for the selection of included studies. SE, sleep efficiency; TST, total sleep time.

\section{Eligibility criteria}

Included studies met the following criteria: (1) participants could be identified as elite athletes (see 'Athlete expertise appraisal' section); (2) the study reported objective (eg, PSG, actigraphy) sleep outcomes; (3) the mean age of participants was $\geq 15$ years; (4) the study was observational or had an observational (ie, control) trial whereby sleep/wake behaviour was not manipulated; (5) the study investigated able-bodied athletes; and (6) the study was published in English as a full-text article in a peer-reviewed journal.

\section{Study selection and data extraction}

After removal of duplicates, the title and abstract of each retrieved record were screened by one reviewer (SSHR). The full text of each screened record was then examined independently by two reviewers (SSHR, SAW) to determine whether the inclusion criteria had been satisfied. Discrepancies were discussed until a consensus was reached. Data from eligible studies were extracted by one reviewer (SSHR) into a spreadsheet designed to record information on the study design and sample population. Data were categorised according to the explanatory variable evident in the study design. The mean and SD for sleep outcomes of interest (see 'Sleep definitions and outcomes of interest' section) were recorded. Where required, SD was calculated from reported CIs. Where data were reported graphically, Plot Digitizer (V.2.6.8) was used to extract numerical values.

\section{Athlete expertise appraisal}

Two reviewers (SSHR, SAW) independently assessed athlete expertise using a modified version of the Model for Classifying the Validity of Expert Samples in Sport Psychology (online supplementary file 2). ${ }^{21}$ The model evaluated three subscale items: the level or performance reached by the athlete, the competitiveness of the sport in the country and the competitiveness of the sport in the world. The modified version was necessary due to limited reporting of athlete experience or success in the literature. Scores were awarded according to the criteria for each item, and a modified algorithm was used to calculate an overall score. ${ }^{9}$ Included studies were required to recruit athletes

\begin{tabular}{|c|c|}
\hline Term & Definition \\
\hline Sleep phase & $\begin{array}{l}\text { The sleep period from the time of day at sleep onset to the } \\
\text { time of day on waking. It is dependent on the circadian } \\
\text { process, and can be delayed or advanced by environmental } \\
\text { or psychosocial factors. }\end{array}$ \\
\hline Sleep pattern & $\begin{array}{l}\text { The consistency or lack of consistency in the sleep phase of } \\
\text { an individual over consecutive days or weeks. }\end{array}$ \\
\hline Bedtime & $\begin{array}{l}\text { The time of day at which an individual goes to bed and } \\
\text { attempts to sleep. }\end{array}$ \\
\hline Sleep onset & $\begin{array}{l}\text { The time of day following bedtime at which sleep } \\
\text { commences. }\end{array}$ \\
\hline Wake time & $\begin{array}{l}\text { The time of day at which the final awakening from a sleep } \\
\text { period occurs. }\end{array}$ \\
\hline Time in bed (TIB) & Total time spent in bed from bedtime to wake time. \\
\hline Sleep period (SP) & Total time from sleep onset to wake time. \\
\hline $\begin{array}{l}\text { Wake after sleep onset } \\
\text { (WASO) }\end{array}$ & $\begin{array}{l}\text { Total time spent awake after the initial sleep onset and } \\
\text { before final awakening (ie, WASO=SP-TST). }\end{array}$ \\
\hline Total sleep time (TST) & Total time spent sleeping (ie, TST=SP-WASO). \\
\hline Sleep efficiency & $\begin{array}{l}\text { TST expressed as a percentage of TIB (ie, TST/TIB } \times 100) \text {. } \\
\text { A measure of sleep quality. }\end{array}$ \\
\hline Sleep onset latency & Time elapsed between bedtime and sleep onset. \\
\hline
\end{tabular}

identifiable as either 'competitive-elite' (ie, competing at the highest level in their sport) or 'semi-elite' (ie, competing below the highest level in their sport). ${ }^{921}$

\section{Evidence quality appraisal}

Two reviewers (SSHR, SAW) independently assessed the methodological quality of each study using an adapted version of the Newcastle-Ottawa Scale (NOS) (online supplementary file 3). ${ }^{22}$ The NOS was adapted for use with cross-sectional studies as previously demonstrated. ${ }^{22}$ The NOS assessed participant selection, control of confounders and outcome reporting using eight subscale items. The criteria for each item were established by two reviewers (SSHR, SAW), so that the evidence quality of each study could be assessed in the context of the aims of the review. Each subscale item was awarded a 'score' according to the extent to which the criteria had been satisfied (eg, $0=$ not satisfied, $1=$ satisfied, 2 =satisfied using a validated tool or established model (two items only)). Discrepancies were discussed until a consensus was reached. The sum of subscale item scores was used to provide an overall assessment of evidence quality for each study (ie, $>7=$ high quality, 5-7=moderate quality, $<5=$ low quality). No risk of bias was undertaken at the outcome level because all included studies objectively measured sleep outcomes.

\section{Sleep definitions and outcomes of interest}

Outcomes examined in this review were total sleep time (TST) and sleep efficiency (SE). These were selected because they provide quantitative measures of sleep quantity (TST) and quality (SE), and are frequently reported in the literature. Table 1 shows the definitions of key sleep-related terms used in this review.

\section{Meta-analysis}

For studies that reported sleep outcomes on multiple nights surrounding competition, random-effects meta-analyses were performed to compute the standardised mean difference (SMD) between studies. Studies deemed of moderate quality or higher following evidence quality appraisal were eligible for the meta-analysis. Analyses were performed for several time-point 
comparisons: A ( -2 vs -1$), \mathrm{B}(-2$ vs 0$), \mathrm{C}(-2$ vs +1$)$, D $(-2$ vs +2$)$ and $E(-1$ vs 0$)$, whereby $-2=$ two nights before, $-1=$ the night before, $0=$ the night of, $+1=$ the night after and $+2=$ two nights after competition day/night. Two nights before competition was selected to represent a 'control' night for analyses because it is most removed from potential sleep influencing factors such as precompetition anxiety and post competition fatigue, whilst still being reported frequently in the literature. The additional comparison $\mathrm{E}$ was included due to the plethora of data in the literature for nights -1 and 0 . Prespecified subgroup analyses and meta-regression were undertaken to assess if 'sleeping environment' (home vs away) and 'competition start time' (day (start time <18:00) vs night (start time $\geq 18: 00)$ ) affected sleep. The size of significant effects was estimated by back transforming pooled SMDs using representative studies, ${ }^{23-25}$ as recommended by previously established guidelines. ${ }^{26}$ The $\mathrm{I}^{2}$ statistic was used to assess statistical heterogeneity, whereby $\mathrm{I}^{2}<25 \%$ was considered low, $\mathrm{I}^{2}=25 \%-50 \%$ was considered moderate and $\mathrm{I}^{2}>50 \%$ was considered high heterogeneity. ${ }^{27}$ We used funnel plots and Egger's regression test (non-significant asymmetry indicated no bias) to assess for publication bias. ${ }^{28}$ Statistical analyses were performed using Comprehensive Meta-Analysis (V.3.0, Biostat, Englewood, USA). An alpha level of $\mathrm{p}<0.05$ was used to determine statistical significance.

\section{RESULTS}

The database search yielded 4066 records. After removal of duplicates and initial screening, the full text of 67 records was examined. Thirteen were excluded for not meeting the inclusion criteria, leaving 54 studies for review (figure 1).

\section{Study characteristics and athlete expertise}

The included studies were published between 1997 and $2018,{ }^{7} 13$ 23-25 29-77 with $81 \%$ ( $\mathrm{n}=44$ studies) published since 2014. 713 23-25 29-34 36-39 41-50 5253 55-57 60-63 65-70 73 747677 Women were recruited by $37 \%$ of studies $(n=20$ studies), ${ }^{713} 323540-445051555661-6365677174$ but only 19\% ( $\mathrm{n}=10$ studies) recruited women exclusively. ${ }^{740} 4155566165677174$ The mean age of athletes ranged from 16 to 28 years; however, one case study recruited a 31-year-old athlete. ${ }^{53}$ Athletes were recruited from 21 sports including soccer $(\mathrm{n}=14),{ }^{25} 36-3842464750525360647273$ Australian rules football $(\mathrm{n}=11)$, $23333945505257-596370$ cycling $(\mathrm{n}=6),{ }^{42} 48-505463$ rugby league $(\mathrm{n}=6),{ }^{29-31396869}$ swimming $(\mathrm{n}=5),{ }^{3250626371}$ rugby union $(\mathrm{n}=5),{ }^{2434505266}$ netball $(\mathrm{n}=6),{ }^{74155566174}$ basketball $(\mathrm{n}=3),{ }^{506367}$ rowing $(\mathrm{n}=3),{ }^{43} 4451$ mountain biking $(\mathrm{n}=3),{ }^{42} 5063$ triathlon $(\mathrm{n}=3),{ }^{425063}$ American football, ${ }^{75} 76$ race walking $(\mathrm{n}=2),{ }^{50} 63$ ice hockey, ${ }^{77}$ diving $(n=1),{ }^{51}$ running $(n=1),{ }^{40}$ volleyball $(n=1),{ }^{42}$ judo $(\mathrm{n}=1),{ }^{13}$ handball $(\mathrm{n}=1),{ }^{42}$ canoeing $(\mathrm{n}=1),{ }^{51}$ speed skating $(\mathrm{n}=1),{ }^{51}$ synchronised swimming $(\mathrm{n}=1)^{65}$ and ballet $\left.(\mathrm{n}=1)\right)^{35}$ 'Competitive-elite' athletes were recruited by $65 \%(n=35)$ of studies, 23-25 29-34 $363839424548-53 \quad 55-5963$ 65-70 747577 and 37\% $(\mathrm{n}=20)$ recruited 'semi-elite' athletes (online supplementary file 2). ${ }^{7132935374041434446475460-626471-7376}$

\section{Evidence quality and data collection methods}

The average evidence quality of included studies was moderate (NOS mean $\pm \mathrm{SD}=7 \pm 1)$, with $28 \%(\mathrm{n}=15)$ considered high quality, ${ }^{731} 3334394250-5257637070 \%(\mathrm{n}=38)$ considered moderate quality, ${ }^{13} 23-25293032$ 35-38 40 41 43-49 53-56 58-62 64-67 69 71-74 and 2\% $(n=1)$ considered low quality (the results for each subscale item are provided in online supplementary file 3$).{ }^{68}$ Studies used actigraphy $(\mathrm{n}=46),{ }^{7} 13 \quad 23-25$ 29-38 40-53 55-63 65-70 7274 PSG $(n=6), 395464717577$ headband electroencephalography $(n=1)^{73}$ or photoplethysmography $(n=1)^{76}$ to monitor sleep. Of those that used actigraphy, 9\% $(n=4)$ used a high sleep-wake threshold (>80 activity counts), ${ }^{29} 30427233 \%(\mathrm{n}=15)$ used a medium threshold ( $>40$ activity counts), ${ }^{723} 36 \quad 41 \quad 45 \quad 47-5052606263 \quad 7078 \quad 18 \% \quad(n=9)$ used the 'Readiband' device-specific algorithm, ${ }^{13} 2531333438555674$ 7\% $(n=3)$ used the 'SenseWear' device-specific algorithm, ${ }^{24} 43442 \%$ $(n=1)$ used the Cole-Kripke algorithm, ${ }^{67} 2 \%(n=1)$ used the Sadeh algorithm ${ }^{37}$ and $2 \%(n=1)$ used a modified version of Cole's algorithm. ${ }^{40}$ The sleep-wake threshold/algorithm was not reported by 29\% (n=13) of studies. $313235465157-596165666869$

\section{Quantitative synthesis}

Thirteen studies reported sleep outcomes for multiple nights surrounding competition and were included in the meta-analysis. $^{23-2530343638455558666779}$ All included studies recruited 'competitive-elite' athletes competing at the highest level in their sport. Pooled effects for each time-point comparison (A-E) are shown in figure 2 (TST) and figure 3 (SE). Funnel plots examining publication bias are provided in online supplementary file 4.

TST was shorter (approximately $60 \mathrm{~min}$ ) the night of compared with two nights before (comparison $\mathrm{B}, \mathrm{p}<0.01$ ) and the night before competition (comparison $\mathrm{E}, \mathrm{p}<0.01$ ) (figure 2). For comparisons B and E, TST was shorter the night of competition in both home $(p<0.01)$ and away $(p<0.01)$ environments. For comparison E, TST was shorter (approximately $80 \mathrm{~min}$ ) the night of night competition $(\mathrm{p}<0.01)$ and shorter (approximately $20 \mathrm{~min})$ the night of day competition $(\mathrm{p}=0.032)$ compared with the night before competition (figure 4$)$. No differences ( $p>0.05$ ) for TST were found for any other time-point (A, C, D) or subgroup comparisons. TST heterogeneity was moderate for comparisons $\mathrm{A}\left(\mathrm{I}^{2}=39 \%\right), \mathrm{C}\left(\mathrm{I}^{2}=48 \%\right)$ and $\mathrm{D}\left(\mathrm{I}^{2}=36 \%\right)$, and high for comparisons $\mathrm{B}\left(\mathrm{I}^{2}=66 \%\right)$ and $\mathrm{E}\left(\mathrm{I}^{2}=76 \%\right)$.

SE was lower (approximately 1\%) the night of competition compared with the night before competition (comparison $\mathrm{E}$, $\mathrm{p}=0.02$ ) (figure 3 ). This effect was driven by night competition, as SE was lower (approximately 3\%) the night of night competition $(p<0.01)$ but unchanged the night of day competition $(p=0.378)$ (figure 4$)$. SE tended to be lower compared with two nights before competition (comparison $\mathrm{B}, \mathrm{p}=0.058$ ). However, when just night competition was examined, SE was lower (approximately 4\%) the night of competition $(p=0.012)$ compared with two nights before (note: meta-analysis of 'day' subgroup for comparison B was not possible due to limited data) figure 5. No differences $(p>0.05)$ for SE were found for any other time-point (A, C, D) or subgroup comparison. Heterogeneity was low for all comparisons $(\mathrm{A}-\mathrm{D}=0 \%, \mathrm{E}=6 \%)$.

\section{Qualitative synthesis}

\section{General sleep characteristics}

Seven studies examined sleep across a competitive week, month or season. ${ }^{7303345496167}$ Of these, few found athletes, on average, did not achieve current recommendations for TST $(n=2 / 7 \text { studies })^{30} 33$ and SE $(n=1 / 7$ studies; online supplementary file 5). ${ }^{33}$ Twenty-one studies examined sleep on one or more individual nights $(-2$ to +2$)$ surrounding the competition. $^{723-25303234363841454953-55585966677274}$ Some studies reported cases where athletes were unable to achieve sleep recommendations on nights -2 (TST: $n=2 / 7$, SE: $n=5 / 6$ studies), $\begin{array}{llllllllll}24 & 25 & 30 & 34 & 38 & 49 & 66 & -1\end{array}$ (TST: $n=2 / 15, \quad S E: n=6 / 13$ studies), ${ }^{23} 25303438495566+1$ (TST: $n=4 / 11$, SE: $n=5 / 9$ 


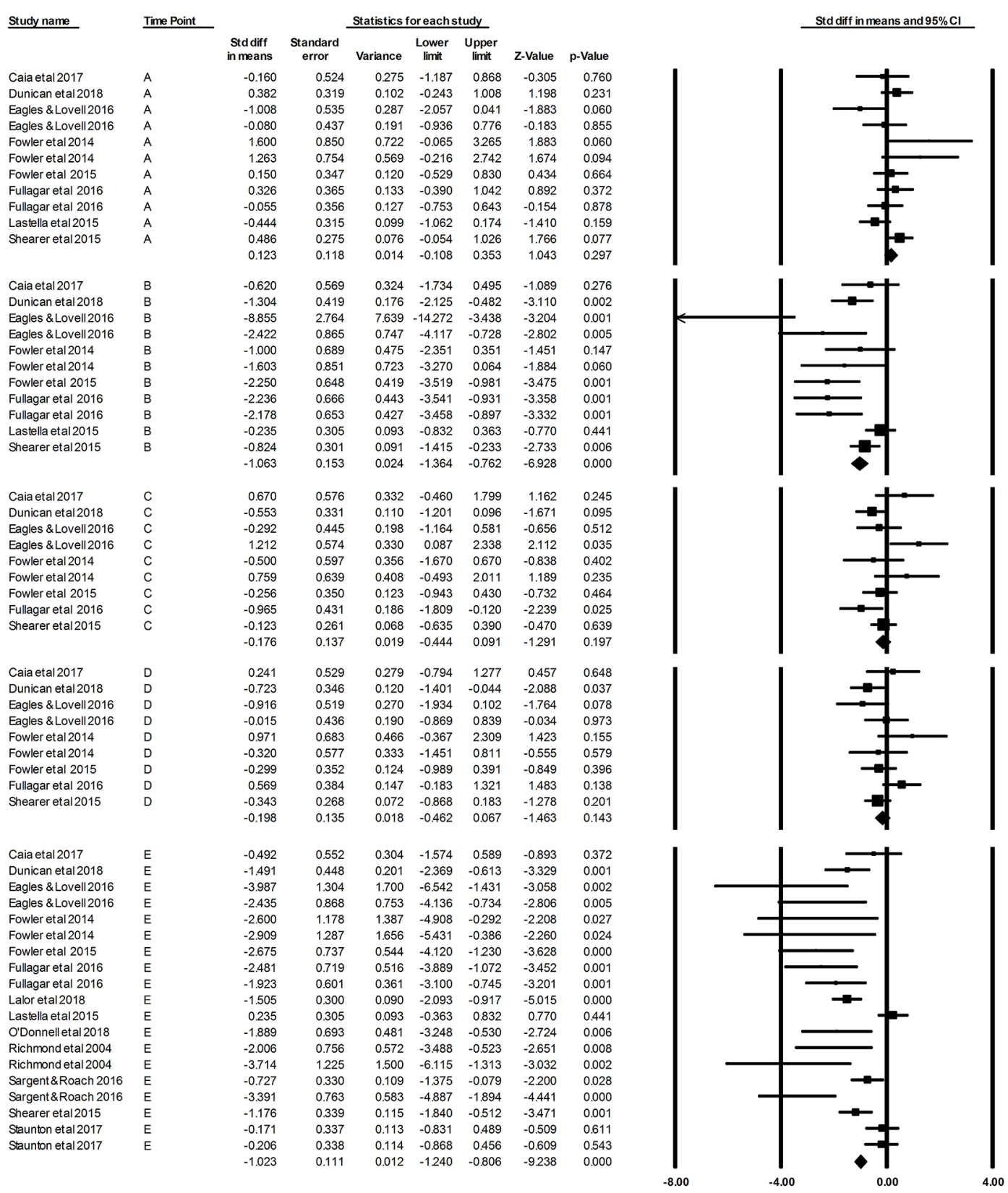

studies) ${ }^{253436385566}$ and +2 (TST: $n=3 / 8$, SE: $n=2 / 6$ studies $) .{ }^{25343666}$ On the night of competition (0), most studies found athletes were unable to achieve recommendations for TST $(n=14 / 18$ studies) $23-253034363849535558667274$ and SE ( $\mathrm{n}=10 / 16$ studies; online supplementary file 6). ${ }^{23253438535558667274}$ Forty-two studies examined sleep during a training or non-competition period. ${ }^{71329-313537394042-5456-5860-6567-77}$ Of these, many reported cases whereby athletes were unable to achieve recommendations for TST ( $=23 / 41$ studies) $)^{29-3135404344464750-535762636568697275-77}$ and SE $(n=16 / 36$ studies; online supplementary file 7). ${ }^{35374345474851565762646569707274}$

\section{The night of competition}

Eighteen studies examined sleep the night of competition. ${ }^{723-25303436-38414553555866677479}$ Shorter TST the night of competition compared with surrounding nights $(-2$ to +2 ) was frequently reported. ${ }^{24} 253034363845555866$ Only three studies reported no difference in TST the night of competition compared with surrounding nights. ${ }^{374967}$ However, one of these found that TST was shorter the night of competition when 'double-header' fixtures (ie, two matches in 3 days) were played, ${ }^{67}$ and another found TST was shorter the night of competition compared with prior training. ${ }^{49}$ Similarly, the TST of netballers was shorter the night of a game compared with the night of a rest day ${ }^{4174}$ and the night of a training day, ${ }^{74}$ while some evidence suggested TST was shorter the night of night-time compared with day competition, ${ }^{723}$ and the night of away compared with home competition. ${ }^{58}$

Most studies reported no change in SE the night of competition compared with surrounding nights or training 


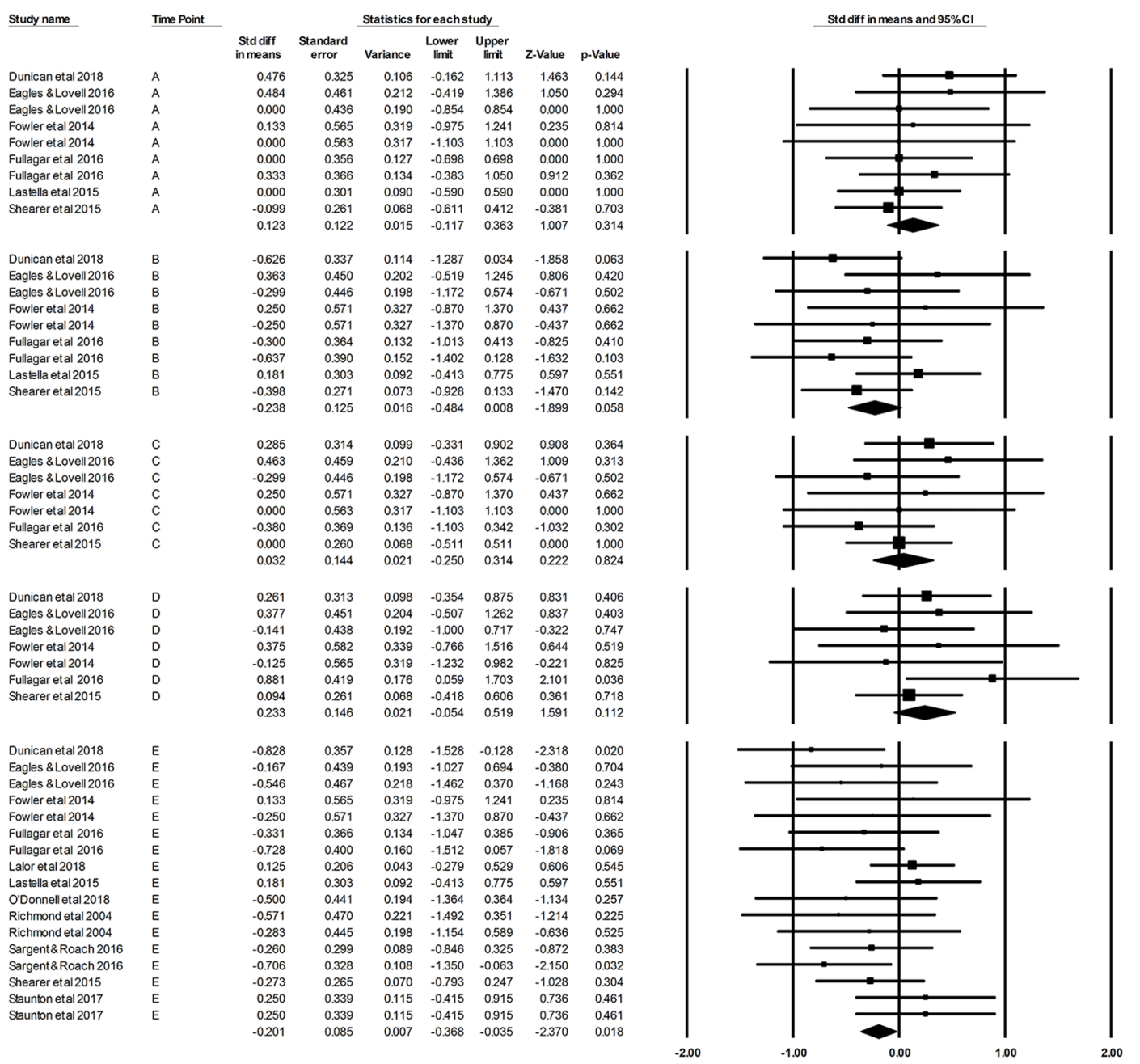

periods. $^{242538454955586667}$ However, SE was lower the night of a match compared with surrounding nights in rugby union players, ${ }^{34}$ and compared with the night of a rest day among netballers. ${ }^{41}$ Similarly, SE was very low $(70 \% \pm 10 \%)$ the night of competition and outside preseason intraindividual variability $(90 \% \pm 3 \%)$ in a soccer player. ${ }^{53}$ However, conversely, compared with sleep monitored during preseason, SE was almost certainly higher the night of competition among Australian rules footballers. ${ }^{45}$

\section{The night before competition}

Fifteen studies examined sleep the night before competition. $^{23-253032363845495358596667}$ Most reported no difference in TST or SE the night before competition compared with surrounding non-competition nights $(-2,+1$, +2). ${ }^{23-2530363845496667}$ However, TST the night before competition was longer compared with the night after $(+1)$ in netballers ${ }^{55}$ and was likely longer than the night after $(+1)$ and two nights after $(+2)$ competition in Australian rules footballers. ${ }^{45}$ Additionally, both TST and SE the night before a match were almost certainly greater than during preseason among Australian rules footballers. ${ }^{45}$ Several other studies found TST to be longer the night before competition compared with prior training. ${ }^{586780}$ However, one study found TST was shorter the night before competition compared with prior training among cyclists. ${ }^{49}$ Interestingly, TST was longer before a final than before a semifinal in swimmers who were unable to achieve a top-four finish at national championships. ${ }^{32}$ Finally, SE was lower on nights prior to a match where an injury occurred (66\%-79\%) than the intraindividual variability $(90 \% \pm 3 \%)$ recorded during preseason. $^{53}$

\section{Training schedule}

Six studies examined the effects of training schedules on sleep. ${ }^{13} 3043626368$ TST was shorter prior to training days than prior to rest days, ${ }^{30436263}$ particularly when training started before 07:00, as in rugby league players during preseason ${ }^{30}$ and rowers/swimmers preparing for competition. ${ }^{43}{ }^{62} \mathrm{No}$ difference in TST prior to training versus rest days was observed in rugby league players when training commenced at $07: 30^{68}$ or $09: 00 .^{30}$ Shifting training start from $06: 30$ to 09:30 increased prior TST in judo athletes, ${ }^{13}$ while a study that examined the effect of different training start times found athletes who started between 05:00 and 06:00 obtained less than 5 hours of TST, and those who started between 10:00 and 11:00 obtained more than 7 hours. ${ }^{63}$ It was predicted that TST will reduce by just $6 \mathrm{~min}$ when start is advanced from 08:00 to 07:00, but by $48 \mathrm{~min}$ when advanced from $08: 00$ to $06: 00 .^{63}$ 


\begin{tabular}{|c|c|c|c|c|c|c|c|c|c|c|}
\hline \multirow{2}{*}{$\begin{array}{l}\text { Group by } \\
\text { Comp Time }\end{array}$} & \multirow[t]{2}{*}{ Study name } & \multirow[t]{2}{*}{ Outcome } & \multirow[t]{2}{*}{ Time Point } & \multicolumn{7}{|c|}{ Statistics for each study } \\
\hline & & & & $\begin{array}{l}\text { Std diff } \\
\text { in means }\end{array}$ & $\begin{array}{c}\text { Standard } \\
\text { error }\end{array}$ & Variance & $\begin{array}{l}\text { Lower } \\
\text { limit }\end{array}$ & $\begin{array}{l}\text { Upper } \\
\text { limit }\end{array}$ & Z-Value & p-Value \\
\hline DAY & Lastella etal 2015 & TST & $\mathrm{E}$ & 0.235 & 0.305 & 0.093 & -0.363 & 0.832 & 0.770 & 0.441 \\
\hline DAY & Richmond etal 2004 & TST & $\mathrm{E}$ & -2.006 & 0.756 & 0.572 & -3.488 & -0.523 & -2.651 & 0.008 \\
\hline DAY & Richmond etal 2004 & TST & $\mathrm{E}$ & -3.714 & 1225 & 1.500 & -6.115 & -1.313 & -3.032 & 0.002 \\
\hline DAY & Sargent\&Roach 2016 & TST & $\mathrm{E}$ & -0.727 & 0.330 & 0.109 & -1.375 & -0.079 & -2.200 & 0.028 \\
\hline DAY & & & & -0.453 & 0.212 & 0.045 & -0.868 & -0.038 & -2.140 & 0.032 \\
\hline NIGHT & Caia etal 2017 & TST & $\mathrm{E}$ & -0.492 & 0.552 & 0.304 & -1.574 & 0.589 & -0.893 & 0.372 \\
\hline NIGHT & Dunican etal 2018 & TST & $\mathrm{E}$ & -1.491 & 0.448 & 0.201 & -2.369 & -0.613 & -3.329 & 0.001 \\
\hline NIGHT & Eagles \& Lovell 2016 & TST & $\mathrm{E}$ & -3.987 & 1.304 & 1.700 & -6.542 & -1.431 & -3.058 & 0.002 \\
\hline NIGHT & Eagles \& Lovell 2016 & TST & $\mathrm{E}$ & -2.435 & 0.868 & 0.753 & -4.136 & -0.734 & -2.806 & 0.005 \\
\hline NIGHT & Fowler etal 2015 & TST & $E$ & -2.675 & 0.737 & 0.544 & -4.120 & -1230 & -3.628 & 0.000 \\
\hline NIGHT & Fullagar etal 2016 & TST & $\mathrm{E}$ & -2.481 & 0.719 & 0.516 & -3.889 & -1.072 & -3.452 & 0.001 \\
\hline NIGHT & Fullagar etal 2016 & TST & $\mathrm{E}$ & -1.923 & 0.601 & 0.361 & -3.100 & -0.745 & -3.201 & 0.001 \\
\hline NIGHT & O'Donnell etal 2018 & TST & $\mathrm{E}$ & -1.889 & 0.693 & 0.481 & -3.248 & -0.530 & -2.724 & 0.006 \\
\hline NIGHT & Sargent\&Roach 2016 & TST & $E$ & -3.391 & 0.763 & 0.583 & -4.887 & -1.894 & -4.441 & 0.000 \\
\hline NIGHT & Shearer etal 2015 & TST & $\mathrm{E}$ & -1.176 & 0.339 & 0.115 & -1.840 & -0.512 & -3.471 & 0.001 \\
\hline NIGHT & & & & -1.699 & 0.185 & 0.034 & -2.061 & -1.336 & -9.186 & 0.000 \\
\hline
\end{tabular}

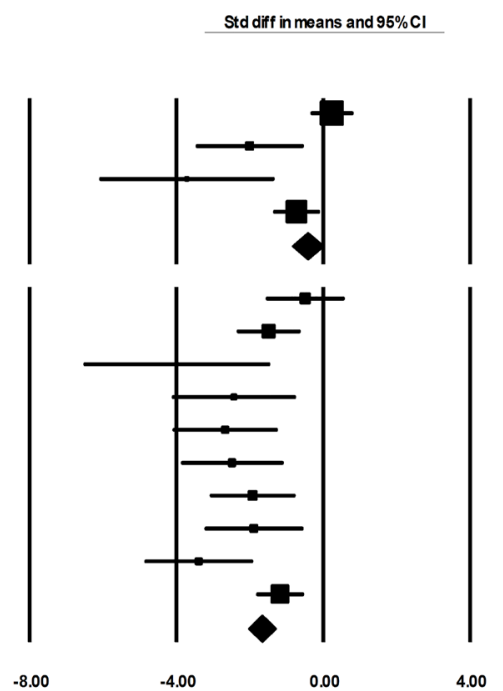

\begin{tabular}{|c|c|c|c|c|c|c|c|c|c|c|}
\hline \multirow{2}{*}{$\frac{\text { Group by }}{\text { Comp Time }}$} & \multirow[t]{2}{*}{ Study name } & \multirow[t]{2}{*}{ Outcome } & \multirow[t]{2}{*}{$\underline{\text { Time Point }}$} & \multicolumn{7}{|c|}{ Statistios for eachstudy } \\
\hline & & & & $\begin{array}{l}\text { Std diff } \\
\text { in means }\end{array}$ & $\begin{array}{l}\text { Standard } \\
\text { error }\end{array}$ & Variance & $\begin{array}{l}\text { Lower } \\
\text { limit }\end{array}$ & $\begin{array}{l}\text { Upper } \\
\text { limit }\end{array}$ & Z-Value & p-Value \\
\hline DAY & Lastella etal 2015 & SE & $\mathrm{E}$ & 0.181 & 0.303 & 0.092 & -0.413 & 0.775 & 0.597 & 0.551 \\
\hline DAY & Richmond etal 2004 & SE & E & -0.571 & 0.470 & 0.221 & -1.492 & 0.351 & -1214 & 0.225 \\
\hline DAY & Richmond etal 2004 & SE & E & -0283 & 0.445 & 0.198 & -1.154 & 0.589 & -0.636 & 0.525 \\
\hline DAY & Sargent\&Roach 2016 & SE & E & -0260 & 0299 & 0.089 & -0.846 & 0.325 & -0.872 & 0.383 \\
\hline DAY & & & & -0.157 & 0.178 & 0.032 & -0.505 & 0.192 & -0.882 & 0.378 \\
\hline NIGHT & Dunican etal 2018 & SE & $\mathrm{E}$ & -0.828 & 0.357 & 0.128 & -1.528 & -0.128 & -2.318 & 0.020 \\
\hline NIGHT & Eagles \&Lovell 2016 & SE & E & -0.167 & 0.439 & 0.193 & -1.027 & 0.694 & -0.380 & 0.704 \\
\hline NIGHT & Eagles \&Lovell 2016 & SE & E & -0.546 & 0.467 & 0.218 & -1.462 & 0.370 & -1.168 & 0.243 \\
\hline NIGHT & Fullagar etal 2016 & SE & $\mathrm{E}$ & -0.331 & 0.366 & 0.134 & -1.047 & 0.385 & -0.906 & 0.365 \\
\hline NIGHT & Fullagar etal 2016 & SE & $\mathrm{E}$ & -0.728 & 0.400 & 0.160 & -1.512 & 0.057 & -1.818 & 0.069 \\
\hline NIGHT & O'Donnell etal 2018 & SE & $\mathrm{E}$ & -0.500 & 0.441 & 0.194 & -1.364 & 0.364 & -1.134 & 0.257 \\
\hline NIGHT & Sargent\&Roach 2016 & SE & E & -0.706 & 0.328 & 0.108 & -1.350 & -0.063 & -2.150 & 0.032 \\
\hline NIGHT & Shearer etal 2015 & SE & E & -0273 & 0265 & 0.070 & -0.793 & 0.247 & -1.028 & 0.304 \\
\hline NIGHT & & & & -0.498 & 0.129 & 0.017 & -0.751 & -0.245 & -3.858 & 0.000 \\
\hline
\end{tabular}

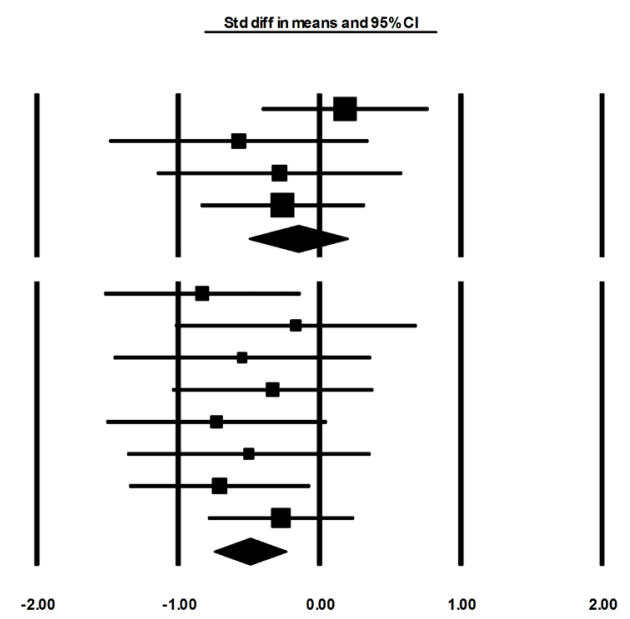

Figure 4 Forest plots showing total sleep time (TST) (top) and sleep efficiency (SE) (bottom) effects for time-point comparison E ( 1 vs 0 ) when subgroup analysis 'competition start time' was applied. Includes data from studies that reported competition started either before (ie, 'day') or after (ie, 'night') 18:00. Effects to the left of 0.00 indicate higher values for the first night of the comparison, wheras effects to the right of 0.00 indicate higher values for the second night of the comparison

Only when training commenced after 09:00 did athletes consistently achieve 7 or more hours of TST. ${ }^{63}$ No effects of training schedule on SE were reported.

\section{Training load}

Eleven studies examined the effects of training load on sleep. ${ }^{3042-4448576065686971}$ Rugby league players, synchronised swimmers and cyclists had reduced TST and SE following large increases (>25\%) in training load. ${ }^{48} 6569$ Rowers also had shorter TST, but no change in SE, during periods of higher training load, ${ }^{43}$ while distance covered during training negatively correlated with subsequent TST $(r=-0.31)$ among rugby league players. ${ }^{69}$ Shorter TST was also observed among rowers in the final days of a training camp compared with subsequent nights at a competition when sleep opportunities increased. ${ }^{44}$ In contrast, among soccer players, no difference in TST or SE was found on nights following light training versus heavy training ${ }^{60}$ and the TST of swimmers was the same during peak and tapered training periods. ${ }^{71}$

Four studies examined sleep in response to day-to-day variations in individual training load. In a study of athletes from several sports, neither TST nor SE was associated with day-to-day variation in load. ${ }^{42}$ However, in rugby league players, a small correlation between within-player load and both TST and SE ( $r=0.11$, respectively) was reported..$^{30}$ Interestingly, the TST of rugby league players was reduced the more within-player training load differed (whether it increased or decreased) from the individual mean training load. ${ }^{57}$ It was also suggested, using magnitude-based inferences, that increased acceleration/deceleration during training may increase SE and TST, ${ }^{68}$ while increased distance covered and distance covered at high speed may lead to lower TST and lower SE, respectively. ${ }^{68}$

\section{Hypoxia}

Four studies examined the effects of hypoxia on sleep. ${ }^{40} 466472$ Three examined soccer players who ascended altitude (ie, hypobaric). ${ }^{46} 6472$ Compared with sleeping near sea level $(430 \mathrm{~m})$, TST at high altitude $(3600 \mathrm{~m})$ was reduced the first night after ascending and on 5 of 12 subsequent nights. ${ }^{72}$ Similarly, SE was reduced on the first night after ascending and on 3 of 12 subsequent nights. ${ }^{72}$ In a subset of these players, PSG found SE and TST were possibly lower on the first few nights of exposure ${ }^{64}$ but that after almost 2 weeks at altitude SE was possibly higher than was recorded at sea level. ${ }^{64}$ Similarly, 


\begin{tabular}{|c|c|c|c|c|c|c|c|c|c|c|}
\hline \multirow{2}{*}{$\frac{\text { Group by }}{\text { Comp Time }}$} & \multirow[t]{2}{*}{ Study name } & \multirow[t]{2}{*}{ Outcome } & \multirow[t]{2}{*}{ Time Point } & \multicolumn{7}{|c|}{ Statistics for each study } \\
\hline & & & & $\begin{array}{l}\text { Std diff } \\
\text { in means }\end{array}$ & $\begin{array}{l}\text { Standard } \\
\text { error }\end{array}$ & Variance & $\begin{array}{c}\text { Lower } \\
\text { limit }\end{array}$ & $\begin{array}{c}\text { Upper } \\
\text { limit }\end{array}$ & z-Value & p-Value \\
\hline NIGHT & Caia etal 2017 & TST & B & -0.620 & 0.569 & 0.324 & -1.734 & 0.495 & -1.089 & 0.276 \\
\hline NIGHT & Dunican etal 2018 & TST & B & -1.304 & 0.419 & 0.176 & -2.125 & -0.482 & -3.110 & 0.002 \\
\hline NIGHT & Eagles \& Lovell2016 & TST & B & -8.855 & 2.764 & 7.639 & -14.272 & -3.438 & -3.204 & 0.001 \\
\hline NIGHT & Eagles \& Lovell 2016 & TST & B & -2.422 & 0.865 & 0.747 & -4.117 & -0.728 & -2.802 & 0.005 \\
\hline NIGHT & Fowler etal 2015 & TST & B & -2.250 & 0.648 & 0.419 & -3.519 & -0.981 & -3.475 & 0.001 \\
\hline NIGHT & Fullagar etal 2016 & TST & B & -2236 & 0.666 & 0.443 & -3.541 & -0.931 & -3.358 & 0.001 \\
\hline NIGHT & Fullagar etal 2016 & TST & B & -2.178 & 0.653 & 0.427 & -3.458 & -0.897 & -3.332 & 0.001 \\
\hline NIGHT & Shearer etal 2015 & TST & B & -0.824 & 0.301 & 0.091 & -1.415 & -0.233 & -2.733 & 0.006 \\
\hline NIGHT & & & & -1.357 & 0.188 & 0.035 & -1.726 & -0.988 & -7.209 & 0.000 \\
\hline
\end{tabular}

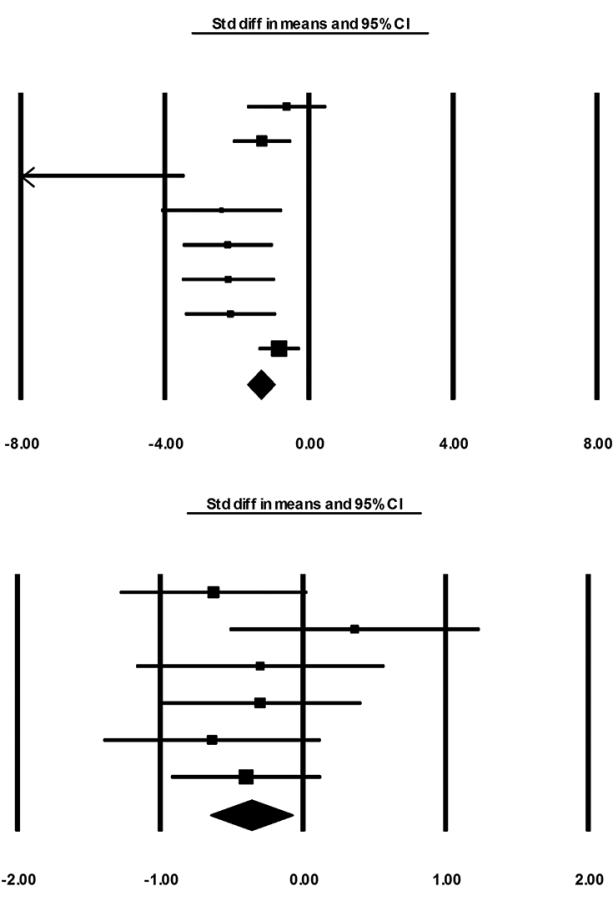

\begin{tabular}{|c|c|c|c|c|c|c|c|c|c|c|}
\hline \multirow{2}{*}{$\frac{\text { Group by }}{\text { Comp Time }}$} & \multirow[t]{2}{*}{ Study name } & \multirow[t]{2}{*}{ Outcome } & \multirow[t]{2}{*}{ Time Point } & \multicolumn{7}{|c|}{ Statistics for each study } \\
\hline & & & & $\begin{array}{l}\text { Std diff } \\
\text { in means }\end{array}$ & $\begin{array}{l}\text { Standard } \\
\text { error }\end{array}$ & Variance & $\begin{array}{l}\text { Lower } \\
\text { limit }\end{array}$ & $\underset{\text { Upper }}{\text { limit }}$ & $z$-Value & p-Value \\
\hline $\mathrm{NIGHT}$ & Dunican etal 2018 & SE & B & -0.626 & 0.337 & 0.114 & -1.287 & 0.034 & -1.858 & 0.063 \\
\hline $\mathrm{NIGHT}$ & Eagles \& Lovell 2016 & $\mathrm{SE}$ & B & 0.363 & 0.450 & 0.202 & -0.519 & 1.245 & 0.806 & 0.420 \\
\hline $\mathrm{NIGHT}$ & Eagles \&Lovell 2016 & SE & B & -0.299 & 0.446 & 0.198 & -1.172 & 0.574 & -0.671 & 0.502 \\
\hline $\mathrm{NIGHT}$ & Fullagar etal 2016 & SE & B & -0.300 & 0.364 & 0.132 & -1.013 & 0.413 & -0.825 & 0.410 \\
\hline $\mathrm{NIGHT}$ & Fullagar etal 2016 & SE & B & -0.637 & 0.390 & 0.152 & -1.402 & 0.128 & -1.632 & 0.103 \\
\hline $\mathrm{NIGHT}$ & Shearer etal 2015 & SE & B & -0.398 & 0.271 & 0.073 & -0.928 & 0.133 & -1.470 & 0.142 \\
\hline NIGHT & & & & -0.367 & 0.147 & 0.021 & -0.655 & -0.080 & -2.507 & 0.012 \\
\hline
\end{tabular}

Figure 5 Forest plots showing total sleep time (TST) (top) and sleep efficiency (SE) (bottom) effects for time-point comparison B ( -2 vs 0 ) when subgroup analysis 'competition start time' was applied. Includes only data from studies reporting a 'night' start time, as only one study reported a 'day' start time for comparison B. Effects to the left of 0.00 indicate higher values for the first night of the comparison, whereas effects to the right of 0.00 indicate higher values for the second night of the comparison.

TST was shorter in the days after travelling from sea level to $1600 \mathrm{~m}$, without being further affected following an additional ascent to $2150 \mathrm{~m} .{ }^{46}$ No changes in TST or SE were observed in runners undertaking six nights of normobaric altitude $(2000 \mathrm{~m})$ exposure. $^{40}$

\section{Air travel}

Eight studies examined the effects of air travel on sleep. 2536384446585972 Early morning and late night departures reduced TST and SE prior to departure compared with non-travel nights. ${ }^{364681}$ Soccer players had shorter TST the first night after long-haul eastward travel compared with baseline sleep. ${ }^{4672}$ However, rowers had longer TST on arrival after longhaul westward travel compared with nights prior to travel. ${ }^{44}$ No change in TST or SE has been observed in response to short-haul travel. 25585 However, in Australian rules footballers, TST was shorter on nights of away matches when a postgame flight was undertaken compared with home matches where no flight was required. ${ }^{58}$

\section{Electronic devices}

Two studies examined the effects of electronic device use on sleep. In judo competitors, the use of electronic devices during a training camp had no effect on TST or SE, ${ }^{13}$ while in netballers no significant association between duration of electronic device use and subsequent sleep outcomes was found during either training or competition. ${ }^{61}$

\section{Additional factors}

One study reported lower SE in male compared with female athletes, ${ }^{51}$ while another found SE was lower when sleeping away compared with sleeping at home despite no air travel or difference in training load between environments. ${ }^{57}$ One study found individual sport athletes have lower TST and SE than team sport athletes, ${ }^{50}$ and one study found professional rugby league players obtained more sleep than semielite players. ${ }^{29}$

\section{Results summary}

The major findings of this review are that (1) athletes are often unable to achieve $\geq 7$ hours of TST and $\geq 85 \%$ SE during training periods or on the night of competition; (2) both TST and SE are reduced the night of competition compared with previous nights, particularly after night (start $\geq 18: 00$ ) competition; (3) athletes typically achieve $\geq 7$ hours of TST and $\geq 85 \%$ SE the night before competition, and neither TST nor $\mathrm{SE}$ is reduced the night before competition compared with surrounding nights; (5) scheduling training before 07:00 reduces TST the night before training and starting after 09:00 may be necessary to consistently achieve $\geq 7$ hours of TST; (6) large increases (ie, $\geq 25 \%$ ) in training load often lead to reductions in both TST and SE; (7) TST and SE may be reduced in the initial days after ascending altitude $(\geq 1600 \mathrm{~m})$; (8) early morning and late night travel departure times reduce TST and SE, while long-haul eastward travel reduces TST immediately on arrival; and (10) no effect of electronic device use on TST or SE has been reported.

\section{DISCUSSION}

This review aimed to (1) characterise the sleep of athletes in the context of current sleep recommendations; and (2) identify factors associated with training and competition that negatively affect sleep.

\section{Sleep characteristics}

Athletes are often unable to achieve $\geq 7$ hours of TST and $\geq 85 \%$ SE during training and on the night of competition. These results are especially concerning as studies with mean data indicating athletes achieve these recommendations likely 
include individuals and/or nights that do not. Previously, athletes recorded a SE below $85 \%$ on $22 \%$ of nights examined despite a mean SE of $88 \% .^{42}$

\section{The night of competition}

Athletes rarely achieved TST or SE recommendations on the night of competition. Meta-analyses found TST and SE were reduced the night of competition compared with precompetition nights, particularly following a night competition. Reductions in TST the night of competition are often attributed to a delay in bedtime, which reduces overall time in bed. ${ }^{232430668182}$ Several factors may explain delayed bedtimes and lower SE the night of competition. For example, increased circulating cortisol, ${ }^{74}$ sympathetic hyperactivity, ${ }^{83}$ elevated core body temperature ${ }^{84}$ and muscle pain ${ }^{85}$ may persist postcompetition and increase arousal. ${ }^{8687}$ Cortisol levels following a race have been negatively $(r=-0.90)$ correlated with SE in swimmers, ${ }^{32}$ while elevated cortisol postcompetition was associated with a reduction in TST the night of competition in netballers. ${ }^{74}$ Additionally, the ergogenic use of caffeine ${ }^{34}$ and exposure to bright light (eg, stadium lighting) may interfere with the neurological processes that promote sleep. ${ }^{88} 89$ In support, increases in salivary caffeine on match day have been correlated with increases in sleep latency $(r=0.53)$ and decreases in SE $(r=0.52)$ in rugby union players. ${ }^{34}$ Finally, delayed bedtimes may be attributed to postcompetition recovery/medical interventions, meetings, travel and media commitments. $^{30} 38$ This review featured predominantly male field sport athletes; thus, poor sleep the night of competition may reflect unique sports-specific challenges faced by these athletes. For example, Australian rules football, rugby union and rugby league are sports characterised by frequent highspeed collisions, ${ }^{90}$ perhaps suggesting postcompetition muscle soreness may contribute to sleep disturbances. ${ }^{87}$ Likewise, within-sport factors, such as travel, may explain sleep disturbances. For example, in Australian rules footballers, TST the night of away games, which required players to fly home immediately postgame, was lower than TST the night of home games that required no travel. ${ }^{58}$ These findings may have implications for the time-course of recovery in the days postcompetition and highlight the need to prioritise sleep during this period.

\section{The night before competition}

Qualitative assessments suggest precompetition sleep disturbances are prevalent among athletes. ${ }^{91-93}$ However, neither the systematic review nor meta-analyses found consistent evidence of this. Compared with training, TST was shorter the night before a race among cyclists, ${ }^{49}$ but longer the night before a match among Australian rules footballers. ${ }^{58} 59$ This review reported that individual sport athletes have lower TST and SE than team sport athletes during out-of-competition training. ${ }^{50}$ However, when sleep was examined prior to competition, comparisons of individual and team sport athletes have delivered equivocal findings. ${ }^{91}{ }^{92}$ Nonetheless, it is suggested that individual athletes, ${ }^{91}$ particularly those competing in aesthetic sports, may be most susceptible to sleep disturbances. ${ }^{94}$ In addition, while this review found SE during training was lower in men compared with women, ${ }^{51}$ there is some evidence that prior to competition sleep disturbances are more prevalent among women. ${ }^{9194}$

The principal cause of precompetition sleep disturbance is anxiety or thoughts about the competition. ${ }^{91} 92$ Individual athletes may experience particularly high levels of anxiety because they cannot share the psychological burden of competition with team members, ${ }^{50} 9194$ which may be exacerbated in aesthetic sport athletes whose success depends on the judgement of others. ${ }^{94}$ Moreover, anxiety disorders have been shown to be more prevalent among female versus male athletes. ${ }^{94}$ Therefore, the limited representation of individual sport, aesthetic sport or female athletes in the present review may explain why consistent evidence for precompetition sleep disturbances were not found.

\section{Early morning training}

Reductions in TST on nights prior to training were noted primarily when training commenced at or before 07:00. It is speculated that shorter TST among individual sport athletes compared with team sport athletes may reflect a tendency for individual sports to commence training early in the morning. ${ }^{50}$ While athletes try to offset the effects of early training by going to bed earlier, it is often difficult to prevent reductions in TST. ${ }^{63}$ For example, on a training camp, rowers woke approximately 2.5 hours earlier on training days compared with rest days, but went to bed just 25 min earlier the night before. ${ }^{43}$ The inability to go to bed early has been attributed to the fact that most social engagements are scheduled in the evening, and the so-called 'forbidden zone'-a period of heightened arousal mediated by the body's circadian rhythms-typically reduces sleep propensity between 20:00 and 22:00. ${ }^{63}$

\section{Increased training load}

TST and SE were reduced following large increases $(>25 \%)$ in training load. ${ }^{48} 6569$ This is consistent with reductions in TST and SE among subelite triathletes following a 30\% increase in training load. ${ }^{95}$ In contrast, most studies that suggested sleep was unaffected or even improved with higher training loads did not involve large increases in training load, rather investigated sleep responses to subtle within-subject changes in load. ${ }^{30} 576871$ Therefore, reductions in TST and SE may reflect a negative adaptation to training in response to large increases in training load. Heavy training can lead to increases in circulating cortisol ${ }^{96}$ and sympathetic activity, ${ }^{97}$ both of which may prevent the normal downregulation of the human stress systems (ie, hypothalamic-pituitary-adrenal, sympathetic-adrenal-medullary) required for healthy sleep. ${ }^{98} 99$ In support, changes in resting alpha-amylase, a marker of sympathetic activity, have been negatively correlated with changes in SE among synchronised swimmers. ${ }^{65}$ Increases in training load may also disturb sleep via pain associated with muscle soreness and frequent micturition at night associated with rehydration efforts.

\section{Hypoxia}

Exposure to high altitude was associated with reductions in TST and SE. This is consistent with previous research suggesting hypoxia causes a shift towards lighter, more fragmented sleep. ${ }^{100}$ Both actual (ie, hypobaric) and simulated (ie, normobaric) altitude exposure have been shown to reduce TST and SE. ${ }^{100} 101$ Sleep disturbances occur predominantly at altitudes above $2000 \mathrm{~m}$ in the initial days after exposure, ${ }^{102}$ and are attributed to arousals caused by the hyperventilatory response to arterial desaturation ${ }^{101}$ and sympathetic hyperactivity. ${ }^{103}$ These findings suggest that when ascending altitude, sufficient time should be allowed for sleep to normalise before training or competition commences. A staged, gradual ascent may expedite this process, as demonstrated in soccer players whose sleep was consistent when ascending from $1600 \mathrm{~m}$ to $2150 \mathrm{~m}$, despite initial reductions in TST after ascending to $1600 \mathrm{~m}^{46}$ 


\section{Air travel}

Sleep disturbances associated with air travel in this review can be attributed to either jet lag (ie, circadian misalignment) or the encroachment of travel times on habitual sleep phase. Both late night and early morning departure times were shown to reduce TST and SE prior to departure, ${ }^{36} 3846$ which may have detrimental effects on athlete preparation. For example, high ratings of fatigue among soccer players following northward travel have been attributed to an early morning flight that reduced TST the night before departure, as jet lag was unlikely given the flight only crossed one time zone. ${ }^{36}$ This review reported lower TST upon arrival after eastward travel, ${ }^{46} 72$ which has also been reported in athletes whose sleep was monitored using self-reported diaries' ${ }^{104}$ In contrast, following westward travel, this review found evidence for an increase in TST on arrival. ${ }^{44}$ However, this finding may be confounded by the fact that pretravel sleep was monitored during a training camp, and that there was an increase in sleep opportunities on arrival. ${ }^{44}$ Nonetheless, there is evidence in subelite athletes that eastward travel is more disruptive to sleep than westward travel. ${ }^{105}$ These findings suggest consideration for the timing of flight departures and the direction of travel is necessary to mitigate the negative effects of air travel.

\section{Electronic devices}

Evening exposure to light, particularly blue light, can cause sleep disturbances. ${ }^{106}$ Delayed bedtimes and reductions in TST have been associated with electronic device use among school-aged children. ${ }^{107108}$ Sleep disturbances are usually attributed to light emitted from such devices that inhibits melatonin release. ${ }^{109}$ However, this review found no evidence that electronic device use in the evening affects the sleep of athletes. ${ }^{1361}$ In support, an examination of the sleep of netballers found that despite melatonin levels rising more in players who read rather than used a tablet device before bed, no difference in subsequent sleep quality or quantity was observed. ${ }^{110}$ Moreover, a study examining high school athletes found that restricting electronic media use after 22:00 did not improve sleep habits. ${ }^{111}$ It may be speculated that the homeostatic pressure for sleep among athletes is such that any negative effects of electronic device use are masked. Blue light has been shown to preferentially reduce slow-wave sleep, ${ }^{112}$ which is the type of sleep believed to promote recovery in athletes and which increases with prior energy expenditure. ${ }^{113}$

\section{Sleep disorders}

This review examined TST and SE in athletes during training and competition. As such, the prevalence of diagnosed sleep disorders was not reported in the results. It is important to acknowledge that the TST and SE outcomes reported in this review may reflect, to some extent, sleep disorders among the athletes investigated. Previous studies have examined the prevalence of sleep disorders among athletes. ${ }^{75-77} 114115$ Mild sleep-disordered breathing has been found to occur in $8 \%$ of college American footballers $^{76}$ and $19 \%$ of professional American footballers. ${ }^{114}$ One in four professional ice hockey players has significant problems sleeping, ${ }^{77}$ while a study examining rugby and cricket players found $38 \%$ defined themselves as snorers. ${ }^{115}$ Athletes with high body mass index, large neck circumference or high levels of adiposity may be at a heightened risk of developing a sleep disorder. ${ }^{76} 114$ This review included relatively few studies that examined such athletes (eg, rugby players); therefore, it is not expected that undiagnosed sleep disorders would affect the findings of the review.

\section{Limitations}

The findings of this review may not reflect the sleep of all athletes, as most reviewed studies recruited male field sport athletes. Only 28\% of the studies included in this review were deemed of high quality, with most concerns arising from small sample sizes and the limited number of sports represented, which make it difficult to apply findings generally to all elite athletes. It is likely that the quality and quantity of sleep vary significantly between athletes and sports. As such, the high heterogeneity of TST reported in the meta-analysis may reflect numerous characteristics that vary between athletes (eg, age, sex, body composition) and the nature of their sport (eg, individual, team, aesthetic, contact). Another factor that may explain high heterogeneity is variation in data collection protocols. Studies that monitored sleep with actigraphy in this review used several different sleep-wake thresholds. This is a concern given the interpretation of data will vary depending on the threshold used. ${ }^{17}$ In addition, while field data are necessary to determine how 'realworld' training and competition pressures affect sleep, an inherent limitation of such data is that potentially confounding factors, such as caffeine and alcohol intake, which may influence sleep, cannot be eliminated or controlled for. Methodological limitations include that initial screening of titles and abstracts was conducted by one reviewer, and that only articles published in English and in peer-reviewed journals were included.

\section{Future research}

Studies using actigraphy to monitor sleep should report the sleep-wake threshold used. There is contradictory evidence for which threshold (ie, medium vs high) is most appropriate for athletes ${ }^{1739}$; therefore, research should explore how athlete type (ie, endurance vs power) and training phase (heavy vs light) affect bias of different thresholds. ${ }^{39}$ Moreover, while it is important to develop strategies that can mitigate sleep disturbances (eg, sleep hygiene) with the aim of improving performance, ${ }^{6}$ more objective data are required to better understand which athletes will benefit and when they will benefit from such strategies. For instance, despite reports that individual sport, aesthetic sport and female athletes are susceptible to sleep disturbances before competition, ${ }^{94}$ there are limited supportive, objective data. Finally, given strong evidence in this review that sleep is disturbed the night of competition, future research should examine whether this affects the time-course of recovery, which may have implications for athlete management postcompetition.

\section{CONCLUSIONS}

This review found that athletes often sleep poorly during training and on the night of competition. Despite previous reports that athletes' sleep is disturbed prior to competition, this is not supported by objectively recorded data. Early morning training, large increases in training load, exposure to hypoxia, travel departure times and jet lag may all negatively affect athletes' sleep. Therefore, sleep during these times should be monitored and prioritised by athletes and support staff. Due to a paucity of literature objectively examining the sleep of individual sport and female athletes, the findings of this review may not reflect the sleep of all athletes.

\section{SUMMARY}

- Athletes are often unable to achieve total sleep time (TST) and sleep efficiency (SE) recommendations during training and on the night of competition (National Sleep Foundation).

- TST and SE are reduced the night of competition compared with previous nights 
- Early morning training, increases in training load, exposure to hypoxic conditions, air travel departure times and jet lag can all negatively affect TST and SE.

- Future research should investigate individual sport and female athletes.

Correction notice This article has been corrected since it was published Online First. Reference 41 has been updated to reflect the actual details of the publication, and a sentence in the 'Air travel' section (page 9) has been edited for clarity.

Acknowledgements The authors thank the authors contacted who provided data and/or information about their published work.

Contributors SSHR contributed to planning, literature search, data extraction, data analysis and writing of the manuscript. W-PT contributed to planning, data analysis and editing of the manuscript. SAW contributed to planning, literature search, data analysis and editing of the manuscript.

Funding This review was undertaken with support from Deakin University.

Competing interests None declared.

Patient consent Not required.

Provenance and peer review Not commissioned; externally peer reviewed.

\section{REFERENCES}

1 Samuels C. Sleep, recovery, and performance: the new frontier in high-performance athletics. Neurol Clin 2008;26:169-80.

2 Chennaoui M, Arnal PJ, Drogou C, et al. Sleep extension increases IGF-I concentrations before and during sleep deprivation in healthy young men. Appl Physiol Nutr Metab 2016;41:963-70.

3 Frank MG, Benington JH. The role of sleep in memory consolidation and brain plasticity: dream or reality? The Neuroscientist 2006;12:477-88.

4 Besedovsky L, Lange T, Born J. Sleep and immune function. Pflügers Archiv - Euro J phy 2012;463:121-37.

5 Venter RE. Perceptions of team athletes on the importance of recovery modalities. Eur J Sport Sci 2014;14(sup 1):S69-76.

6 Bonnar D, Bartel K, Kakoschke N, et al. Sleep Interventions designed to improve athletic performance and recovery: a systematic review of current approaches. Sports Medicine 2018:48:683-703.

7 Juliff LE, Halson SL, Hebert JJ, et al. Longer sleep durations are positively associated with finishing place during a national multiday netball competition. J Strength Cond Res 2018;32:189-94.

8 Milewski MD, Skaggs DL, Bishop GA, et al. Chronic lack of sleep is associated with increased sports injuries in adolescent athletes. J Pediatr Orthoped 2014;34:129-33.

9 Gupta L, Morgan K, Gilchrist S. Does elite sport degrade sleep quality? A systematic review. Sports Medicine 2017;47:1317-33.

10 Ohayon M, Wickwire EM, Hirshkowitz M, et al. National sleep foundation's sleep quality recommendations: first report. Sleep Health 2017;3:6-19.

11 Hirshkowitz M, Whiton K, Albert SM, et al. National sleep foundation's sleep time duration recommendations: methodology and results summary. Sleep Health 2015;1:40-3.

12 Knufinke M, Nieuwenhuys A, Geurts SAE, et al. Self-reported sleep quantity, quality and sleep hygiene in elite athletes. J Sleep Res 2018;27:78-85.

13 Dunican IC, Martin DT, Halson SL, et al. The effects of the removal of electronic devices for 48 hours on sleep in elite judo athletes. J Strength Cond Res 2017:31:2832-9.

14 Kushida CA, Littner MR, Morgenthaler T, et al. Practice parameters for the indications for polysomnography and related procedures: an update for 2005. Sleep 2005;28:499-523.

15 George CFP, Kab V, Levy AM. Increased prevalence of sleep-disordered breathing among professional football players. N Eng/ J Med Overseas Ed 2003;348:367-8.

16 Gosselin N, Lassonde M, Petit D, et al. Sleep following sport-related concussions. Sleep Med 2009;10:35-46.

17 Sargent C, Lastella M, Halson SL, et al. The validity of activity monitors for measuring sleep in elite athletes. J Sci Med Sport 2016:19:848-53.

18 Ancoli-Israel S, Cole R, Alessi C, et al. The role of actigraphy in the study of sleep and circadian rhythms. Sleep 2003;26:342-92.

19 Stroup DF, Berlin JA, Morton SC, et al. Meta-analysis of observational studies in epidemiology: a proposal for reporting. Jama 2000:283:2008-12.

20 Liberati A, Altman DG, Tetzlaff J, et al. The PRISMA statement for reporting systematic reviews and meta-analyses of studies that evaluate health care interventions: explanation and elaboration. PLoS Med 2009;6:e1000100.

21 Swann C, Moran A, Piggott D. Defining elite athletes: Issues in the study of expert performance in sport psychology. Psychol Sport Exerc 2015;16:3-14.

22 Herzog R, Álvarez-Pasquin Ma José, Díaz C, et al. Are healthcare workers' intentions to vaccinate related to their knowledge, beliefs and attitudes? a systematic review. BMC Public Health 2013;13:154.
23 Sargent C, Roach GD. Sleep duration is reduced in elite athletes following night-time competition. Chronobiol Int 2016:33:667-70.

24 Eagles AN, Lovell DI. Changes in sleep quantity and efficiency in professional rugby union players during home-based training and match play. J Sports Med Phys Fitness 2016;56:565-71.

25 Fowler P, Duffield R, Vaile J. Effects of domestic air travel on technical and tactical performance and recovery in soccer. Int I Sports Physiol Perform 2014;9:378-86.

26 Higgins JP, Green S. Cochrane handbook for systematic reviews of interventions: John Wiley \& Sons, 2011.

27 Huedo-Medina TB, Sánchez-Meca J, Marín-Martínez F, et al. Assessing heterogeneity in meta-analysis: Q statistic or $I^{2}$ index? Psychol Methods 2006;11:193-206.

28 Egger M, Smith GD, Schneider M, et al. Bias in meta-analysis detected by a simple, graphical test. BMJ 1997;315:629-34.

29 Caia J, Halson SL, Scott TJ, et al. Intra-individual variability in the sleep of senior and junior rugby league athletes during the competitive season. Chronobiol Int 2017;34:1239-47.

30 Caia J, Scott TJ, Halson SL, et al. Do players and staff sleep more during the pre- or competitive season of elite rugby league? Eur I Sport Sci 2017;17:964-72.

31 Caia J, Thornton HR, Kelly VG, et al. Does self-perceived sleep reflect sleep estimated via activity monitors in professional rugby league athletes? I Sports Sci 2018:36:1-5

32 Chennaoui M, Bougard C, Drogou C, et al. Stress biomarkers, mood states, and sleep during a major competition: success and failure athlete's profile of high-level swimmers. Front Physiol 2016;7.

33 Dennis J, Dawson B, Heasman J, et al. Sleep patterns and injury occurrence in elite Australian footballers. J Sci Med Sport 2016:19:113-6.

34 Dunican IC, Higgins CC, Jones MJ, et al. Caffeine use in a super rugby game and its relationship to post-game sleep. Eur J Sport Sci 2018 18:513-23.

35 Fietze I, Strauch J, Holzhausen M, et al. Sleep quality in professional ballet dancers. Chronobiol Int 2009:26:1249-62.

36 Fowler P, Duffield R, Howle K, et al. Effects of Northbound Long-Haul International air travel on sleep quantity and subjective jet lag and wellness in professional Australian Soccer Players. Int I Sports Physiol Perform 2015;10:648-54.

37 Fowler PM, Paul DJ, Tomazoli G, et al. Evidence of sub-optimal sleep in adolescent Middle Eastern academy soccer players which is exacerbated by sleep intermission proximal to dawn. Eur J Sport Sci 2017;17:1110-8.

38 Fullagar HHK, Duffield R, Skorski S, et al. Sleep, travel, and recovery responses of National footballers during and after Long-Haul International air travel. Int I Sports Physiol Perform 2016:11:86-95.

39 Fuller KL, Juliff L, Gore CJ, et al. Software thresholds alter the bias of actigraphy for monitoring sleep in team-sport athletes. J Sci Med Sport 2017;20:756-60.

40 Hoshikawa M, Suzuki Y, Oriishi M. Effects of normobaric hypoxia equivalent to 2,000-m altitude on sleep and physiological conditions of athletes. J Strength Cond Res 2013:27:2309-13.

41 Juliff LE, Peiffer JJ, Halson SL. Night Games and Sleep: Physiological, Neuroendocrine and Psychometric Mechanisms. Int I Sports Physiol Perform 2018:13:867-73.

42 Knufinke M, Nieuwenhuys A, Geurts SAE, et al. Train hard, sleep well? Perceived training load, sleep quantity and sleep stage distribution in elite level athletes. I Sci Med Sport 2018;21.

43 Kölling S, Steinacker JM, Endler S, et al. The longer the better: sleep-wake patterns during preparation of the world rowing junior championships. Chronobiol Int 2016:33:73-84

44 Kölling S, Treff $\mathrm{G}$, Winkert $\mathrm{K}$, et al. The effect of westward travel across five time zones on sleep and subjective jet-lag ratings in athletes before and during the 2015's World Rowing Junior Championships. J Sports Sci 2017:35:2240-8.

45 Lalor BJ, Halson SL, Tran J, et al. No compromise of competition sleep compared with habitual sleep in Elite Australian Footballers. Int I Sports Physiol Perform 2018;13:29-36

46 Lastella M, Roach GD, Halson SL, et al. The effects of transmeridian travel and altitude on sleep: preparation for football competition. J Sports Sci Med 2014:13:718.

47 Lastella M, Roach GD, Halson SL, et al. Sleep at the helm: a case study of how a head coach sleeps compared to his team. Int I Sports Sci Coach 2017:12:782-9.

48 Lastella M, Roach GD, Halson SL, et al. The impact of a simulated grand tour on sleep, mood, and well-being of competitive cyclists. J Sports Med Phys Fitness 2015:55:1555-64.

49 Lastella M, Roach GD, Halson SL, et al. Sleep/wake behaviour of endurance cyclists before and during competition. J Sports Sci 2015:33:293-9.

50 Lastella M, Roach GD, Halson SL, et al. Sleep/wake behaviours of elite athletes from individual and team sports. Eur I Sport Sci 2015;15:94-100.

51 Leeder J, Glaister M, Pizzoferro K, et al. Sleep duration and quality in elite athletes measured using wristwatch actigraphy. J Sports Sci 2012;30:541-5.

52 Miller DJ, Sargent C, Vincent GE, et al. Sleep/wake behaviours in elite athletes from three different football codes. J Sports Sci Med 2017:16:604-5

53 Nédélec M, Leduc C, Dawson B, et al. Case study: sleep and injury in elite soccer. A mixed method approach. J Strength Cond Res 2017 (Published 21 Sep 2017).

54 Netzer NC, Kristo D, Steinle H, et al. REM sleep and catecholamine excretion: a study in elite athletes. Eur J Appl Physiol 2001;84:521-6. 
55 O'Donnell S, Beaven CM, Driller M. Sleep/wake behavior prior to and following competition in elite female netball athletes. Sport Sci Health 2018;14:289-95.

56 O'Donnell S, Driller MW. Sleep-hygiene education improves sleep indices in elite female athletes. 2017.

57 Pitchford NW, Robertson SJ, Sargent C, et al. Sleep quality but not quantity altered with a change in training environment in elite Australian rules football players. Int J Sports Physiol Perform 2017;12:75-80.

58 Richmond L, Dawson B, Hillman DR, et al. The effect of interstate travel on sleep patterns of elite Australian rules footballers. J Sci Med Sport 2004;7:186-96.

59 Richmond LK, Dawson B, Stewart G, et al. The effect of interstate travel on the sleep patterns and performance of elite Australian rules footballers. J Sci Med Sport 2007; 10:252-8.

60 Robey E, Dawson B, Halson S, et al. Sleep quantity and quality in elite youth soccer players: A pilot study. Eur J Sport Sci 2014;14:410-7.

61 Romyn G, Robey E, Dimmock JA, et al. Sleep, anxiety and electronic device use by athletes in the training and competition environments. Eur J Sport Sci 2016;16:301-8.

62 Sargent C, Halson S, Roach GD. Sleep or swim? Early-morning training severely restricts the amount of sleep obtained by elite swimmers. Eur J Sport Sci 2014;14:S310-15.

63 Sargent C, Lastella M, Halson SL, et al. The impact of training schedules on the sleep and fatigue of elite athletes. Chronobiol Int 2014;31:1160-8.

64 Sargent C, Schmidt WF, Aughey RJ, et al. The impact of altitude on the sleep of young elite soccer players (ISA3600). Br J Sports Med 2013:47(Suppl 1):i86-i92.

65 Schaal K, LE Meur Y, Louis J, et al. Whole-body cryostimulation limits overreaching in elite synchronized swimmers. Med Sci Sports Exerc 2015:47:1416-25.

66 Shearer DA, Jones RM, Kilduff LP, et al. Effects of competition on the sleep patterns of elite rugby union players. Eur J Sport Sci 2015;15:681-6.

67 Staunton C, Gordon B, Custovic E, et al. Sleep patterns and match performance in elite Australian basketball athletes. J Sci Med Sport 2017;20:786-9.

68 Thornton HR, Delaney JA, Duthie GM, et al. Effects of preseason training on the sleep characteristics of professional Rugby League players. Int I Sports Physiol Perform 2018:13:176-82

69 Thornton HR, Duthie GM, Pitchford NW, et al. Effects of a 2-week high-intensity training camp on sleep activity of professional rugby league athletes. Int I Sports Physiol Perform 2017;12:928-33.

70 Van Ryswyk E, Weeks R, Bandick L, et al. A novel sleep optimisation programme to improve athletes' well-being and performance. Eur J Sport Sci 2017;17:144-51.

71 Taylor SR, Rogers GG, Driver HS. Effects of training volume on sleep, psychological, and selected physiological profiles of elite female swimmers. Med Sci Sports Exerc 1997;29:688-93.

72 Roach GD, Schmidt WF, Aughey RJ, et al. The sleep of elite athletes at sea level and high altitude: a comparison of sea-level natives and high-altitude natives (ISA3600) Br J Sports Med 2013:47:i114-i120.

73 Whitworth-Turner C, Di Michele R, Muir I, et al. A shower before bedtime may improve the sleep onset latency of youth soccer players. Eur J Sport SCi 2017;17:1119-28.

74 O'Donnell S, Bird S, Jacobson G, et al. Sleep and stress hormone responses to training and competition in elite female athletes. Eur J Sport Sci 2018;18:1-8.

75 George C, et al. Sleep and breathing in professional football players. Sleep Med 2003;4:317-25.

76 Dobrosielski DA, Nichols D, Ford J, et al. Estimating the prevalence of sleep-disordered breathing among collegiate football players. Respir Care 2016;61:1144-50.

77 Tuomilehto H, Vuorinen VP, Penttilä E, et al. Sleep of professional athletes: Underexploited potential to improve health and performance. J Sports Sci 2017;35:1-7.

78 Nédélec M, Halson S, Delecroix B, et al. Sleep hygiene and recovery strategies in elite soccer players. Sports Med 2015:45:1547-59.

79 Lastella M, Roach GD, Halson SL, et al. Sleep/wake behaviour of endurance cyclists before and during competition. J Sports Sci 2015;33

80 Richmond LK, Dawson B, Stewart G, et al. The effect of interstate travel on the sleep patterns and performance of elite Australian Rules footballers. J Sci Med Sport 2007:10:252-8.

81 Fullagar HHK, Duffield R, Skorski S, et al. Sleep, travel, and recovery responses of national footballers during and after Long-Haul International air travel. Int I Sports Physiol Perform 2016;11:86-95.

82 Fullagar HHK, Skorski S, Duffield R, et al. Impaired sleep and recovery after night matches in elite football players. J Sports Sci 2016;34:1333-9.

83 Kivlighan KT, Granger DA. Salivary alpha-amylase response to competition: relation to gender, previous experience, and attitudes. Psychoneuroendocrinology 2006:31:703-14

84 Veale JP, Pearce AJ. Physiological responses of elite junior Australian rules footballers during match-play. J Sports Sci Med 2009;8:314-9.
85 Hainline B, Derman W, Vernec A, et al. International olympic committee consensus statement on pain management in elite athletes. Br J Sports Med 2017:51:1245-58.

86 Bonnet MH, Arand DL. Hyperarousal and insomnia: State of the science. Sleep Med Rev 2010:14:9-15.

87 Moldofsky H. Sleep and pain. Sleep Med Rev 2001;5:385-96

88 Davis JM, Zhao Z, Stock HS, et al. Central nervous system effects of caffeine and adenosine on fatigue. Am J Physiol Regul Integr Comp Physiol 2003;284:R39 9-R404

89 Zeitzer JM, Dijk DJ, Kronauer R, et al. Sensitivity of the human circadian pacemaker to nocturnal light: melatonin phase resetting and suppression. J Physiol 2000:526:695-702

90 Cummins C, Orr R. Analysis of physical collisions in elite national rugby league match play. Int J Sports Physiol Perform 2015;10:732-9.

91 Erlacher D, Ehrlenspiel F, Adegbesan OA, et al. Sleep habits in German athletes before important competitions or games. J Sports Sci 2011;29:859-66.

92 Juliff LE, Halson SL, Peiffer JJ. Understanding sleep disturbance in athletes prior to important competitions. J Sci Med Sport 2015:18:13-18.

93 Ehrlenspiel F, Erlacher D, Ziegler M. Changes in subjective sleep quality before a competition and their relation to competitive anxiety. Behav Sleep Med 2016;2:1-14.

94 Schaal K, Tafflet M, Nassif H, et al. Psychological balance in high level athletes: gender-based differences and sport-specific patterns. PLoS One 2011;6:e19007.

95 Hausswirth C, Louis J, Aubry A, et al. Evidence of disturbed sleep and increased illness in overreached endurance athletes. Med Sci Sports Exerc 2014;46:1036-45.

96 Balsalobre-Fernández C, Tejero-González Carlos Mª del Campo-Vecino J. Relationships between training load, salivary cortisol responses and performance during season training in middle and long distance runners. PLoS One 2014;9:e106066.

97 lellamo F, et al. Conversion from vagal to sympathetic predominance with strenuous training in high-performance world class athletes. Circulation 2002; 105:2719-24

98 Burgess HJ, Trinder J, Kim Y, et al. Sleep and circadian influences on cardiac autonomic nervous system activity. Am J Physiol Heart Circ Physiol 1997:273:H1761-68.

99 Buckley TM, Schatzberg AF. On the interactions of the hypothalamic-pituitary-adrenal (HPA) axis and sleep: normal HPA axis activity and circadian rhythm, exemplary sleep disorders. J Clin Endocrinol Metab 2005;90:3106-14.

100 Johnson PL, Edwards N, Burgess KR, et al. Sleep architecture changes during a trek from 1400 to $5000 \quad m$ in the Nepal Himalaya. J Sleep Res 2010;19:148-56.

101 Salvaggio A, Insalaco G, Marrone 0, et al. Effects of high-altitude periodic breathing on sleep and arterial oxyhaemoglobin saturation. Eur Respir J 1998;12:408-13.

102 Buguet A. Sleep under extreme environments: effects of heat and cold exposure, altitude, hyperbaric pressure and microgravity in space. J Neuro/ SC 2007;262:145-52.

103 Hainsworth R, Drinkhill MJ, Rivera-Chira M. The autonomic nervous system at high altitude. Clin Auton Res 2007;17:13-19.

104 Fowler PM, McCall A, Jones M, et al. Effects of long-haul transmeridian travel on player preparedness: case study of a national team at the 2014 FIFA World Cup. J SCi Med Sport 2017:20:322-7.

105 Fowler PM, Knez W, Crowcroft S, et al. Greater effect of east versus west travel on jet lag, sleep, and team sport performance. Med Sci Sports Exerc 2017:49:2548-61.

106 Burkhart K, Phelps JR. Amber lenses to block blue light and improve sleep: a randomized trial. Chronobiol Int 2009;26:1602-12.

107 Hysing M, Pallesen S, Stormark KM, et al. Sleep and use of electronic devices in adolescence: results from a large population-based study. BMJ Open 2015;5:e006748.

108 Cain N, Gradisar M. Electronic media use and sleep in school-aged children and adolescents: a review. Sleep Med 2010;11:735-42.

109 Chang AM, Aeschbach D, Duffy JF, et al. Evening use of light-emitting ereaders negatively affects sleep, circadian timing, and next-morning alertness. Proc Nat/ Acad SciU SA 2015:112:1232-7.

110 Jones MJ, Peeling P, Dawson B, et al. Evening electronic device use: the effects on alertness, sleep and next-day physical performance in athletes. J Sports Sci 2018:36:1-9.

111 Harris A, Gundersen H, Mørk-Andreassen P, et al. Restricted use of electronic media, sleep, performance, and mood in high school athletes-a randomized trial. Sleep Health 2015:1:314-21.

112 Chellappa SL, Steiner R, Oelhafen P, et al. Acute exposure to evening blue-enriched light impacts on human sleep. J Sleep Res 2013:22:573-80.

113 Shapiro CM, Bortz R, Mitchell D, et al. Slow-wave sleep: a recovery period after exercise. Science 1981:214:1253-4.

114 Rice TB, Dunn RE, Lincoln AE, et al. Sleep-disordered breathing in the National Football League. Sleep 2010;33:819-24.

115 Swinbourne R, Gill N, Vaile J, et al. Prevalence of poor sleep quality, sleepiness and obstructive sleep apnoea risk factors in athletes. Eur J Sport Sci 2016;16:850-8. 